\title{
PERLINDUNGAN ANAK TERHADAP KEKERASAN SEKSUAL DI KOTA MAKASSAR
}

\author{
Muhammad Anis \\ Universitas Islam Negeri Alauaddin Makassar
}

\begin{abstract}
Sexual violence against children is one of the serious problems we face today, various elements, especially the government, are related to the government's efforts in implementing the Child Protection Act Number 35 of 2014. On the other hand, child victims of sexual violence are part of an immature community its development both physically and psychologically, so it requires special assistance in handling it. Sexual violence against children is an act of violence perpetrated by a community whose physical or psychological development is insufficient or immature so that it requires ongoing assistance specifically relating to its handling. The cause of the occurrence of acts of sexual violence against children is due to family factors, such as parenting that allows their children to get along freely which results in the child losing his identity, the factor of parents not equipping children with religious knowledge which consequently children don't understand what can be done and which can't done, the influence of the environment and many more factors that can cause acts of sexual violence in children. So that children don't experience acts of sexual violence against children, it should be as parents should set an example to children, provide the best examples for children about how to live in accordance with our religion and culture, so that children avoid sexual violence, there must be assistance or supervision strict on children.
\end{abstract}

Keywords: Child Protection, Makassar City, Sexual Violence.

\begin{abstract}
Abstrak
Kekerasan seksual terhadap anak merupakan salah satu permasalahan serius yang kita hadapi saat ini, berbagai elemen terutama pemerintah dikarenakan berkaitan dengan upaya pemerintah dalam melaksanakan Undang-Undang perlindungan anak Nomor 35 Tahun 2014. Disisi lain, anak korban kekerasan seksual merupakan bagian dari masyarakat yang belum matang perkembangannya baik secara fisik maupun psikologis, sehingga membutuhkan pendampingan khusus dalam penanganannya. Kekerasan seksual terhadap anak adalah tindak kekerasan yang dilakukan oleh masyarakat yang kurang atau belum matang perkembangan fisik maupun psikisnya sehingga membutuhkan pendampingan yang berkesinambungan terkhusus yang berhubungan dengan penanganannya. Penyebab terjadinya tindakan kekerasan seksual terhadap anak karena faktor
\end{abstract}


keluarga, seperti Pola Asuh yang membiarkan anaknya bergaul dengan bebas yang berakibat anak kehilangan jati diri, faktor orang tua tidak membekali anak dengan ilmu agama yang akibatnya anak tidak memahami yang mana bisa dilakukan dan mana yang tidak bisa dilakukan, pengaruh lingkungan dan masih banyak lagi faktor yang dapat menyebabkan terjadinya tindak kekrasan seksual pada anak. Agar anak tidak mengalami tindak kekerasan seksual pada anak, hendaknya sebagai orang tua harus memberi keteladanan kepada anak, memberikan contoh yang terbaik kepada anak tentang bagaimana pola hidup yang sesuai dengan agama dan budaya kita, agar anak terhindar dari kekerasan seksual, harus ada pendampingan atau pengawasan yang ketat terhadap anak.

Kata Kunci : Kekerasan Seksual, Kota Makassar, Perlindungan Anak.

\section{PENDAHULUAN}

Anak adalah merupakan karunia dari Allah swt yang senantiasa dijaga dan dilindungi, Seorang anak dilahirkan kedunia ini dalam keadaan suci, anak adalah merupakan buah hati yang senantiasa dijaga dan dilindungi. Orang tua dan lingkungan sangat berperan dalam memberikan warna pada kehidupan anak. Dari orang tua dan lingkunganlah mereka belajar mana perilaku yang baik dan mana perilaku yang buruk. Pembentukan perilaku atau karakter anak dimulai sejak usia dini melalui kebiasaan sehari-hari dirumah bersama orang tua, saudara kandung, keluarga lainnya dan teman bermain. Anak menurut Kitab Undang-undang Hukum Perdata Pasal 330 Kitab Undang-undang Hukum Perdata (KUHPerdata) menyatakan bahwa belum dewasa adalah mereka yang belum mencapai umur genap dua puluh satu tahun, dan tidak lebih dahulu telah kawin.

Sejak tahun 1979 pemerintah telah menetapkan sebuah peraturan untuk meletakkan anak-anak dalam sebuah lembaga proteksi yang cukup aman,yaitu dengan UU No. 4 tentang Kesejahteraan Anak yang dengan tegas merumuskan setiap anak berhak atas pemeliharaan dan perlindungan sejak dalam kandungan sampai dengan sesudah dilahirkan. Langkah pemerintah selanjutnya adalah dengan menetapkan UU Pengadilan Anak (UU No. 3 Tahun 1997) yang diharapkan anak yang berada dalam proses hukum tetap untuk mendapatkan haknya. Terakhir, pemerintah menetapkan UU No. 35 Tahun 2014 perubahan atas UU No. 23 Tahun 2002 tentang Perlindungan Anak yang secara tegas menggariskan bahwa anak adalah penerus bangsa yang harus dijamin perlindungannya dari segala bentuk kekerasan dan diskriminasi.

Namun meskipun Undang-undang No. 35 Tahun 2014 tentang perlindungan anak telah disahkan, tetapi pelaksaan lapangan belum berjalan seperti yang diharapkan. Sedangkan, UU perlindungan anak ini diadakan dengan tujuan menjamin terpenuhinya hak-hak anak agar dapat hidup, tumbuh, berkembang, dan 
berpartisipasi optimal sesuai harkat dan martabat kemanusiaan, serta mendapat perlindungan dari kekerasan dan diskriminasi.

Kekerasan terhadap anak sering kali diidentikkan dengan kekerasan kasat mata, seperti kekerasan fisikal dan seksual. Padahal, kekerasan yang bersifat psikis dan sosial (stuktural) juga membawa dampak buruk permanen terhadap anak. Karenanya, istilah child abuse atau perlakuan salah terhadap anak bisa terentang mulai dari yang bersifat fisik (physical) hingga seksual (sexual abuse) ; dari yang bermatra psikis (mental abuse) hingga sosial (social abuse) yang berdimensi kekerasan stuktural.

Sebagaimana dalam Q.S Ali-Imran / 3: 159:

Terjemahannya:

"Maka disebabkan rahmat dari Allah-lah kamu Berlaku lemah lembut terhadap mereka. Sekiranya kamu bersikap keras lagi berhati kasar, tentulah mereka menjauhkan diri dari sekelilingmu.karena itu ma'afkanlah mereka, mohonkanlah ampun bagi mereka, dan bermusyawaratlah dengan mereka dalam urusan itu”.

Dalam Surah ini Allah menyuruh manusia untuk berbuat lemah lembut. Dalam perkataan maupun perbuatan. Meskipun telah ada larangan didalam Al Qur'an namun tetap saja kekerasan pada anak sering terjadi. Sebagian mempercayai bahwa hal tersebut dapat membuat mereka berhasil dan tidak bermental lemah di masa tua. Jelas argumen semacam ini tidak berdasar. Budaya kekerasan tidak akan menghasilkan apa-apa.

\section{METODE PENELITIAN}

Penelitian ini berfokus pada Perlindungan anak terhadap kekerasan seksual yang berdasar pada Al-Qur'an dan mengacu pada UU No.35 Tahun 2014 tentang perlindungan anak terhadap kekerasan seksual di Kota Makassar (Kel Tamparang Keke, Kecamatan Mamajang).

\section{PEMBAHASAN}

\section{A. Tinjauan Umum Mengenai Kekerasan Seksual terhadap Anak}

Pengertian kekerasan Seksual terhadap anak dalam istilah sangat terkait dengan kata Abuse yaitu kata yang biasa diterjemahkan menjadi kekerasan, penganiayaan, penyiksaan, atau perlakuan salah. ${ }^{l}$ Kata ini didefinisikan sebagai "improper behavior intended to cause phisycal, psychological, or financial harm to an individual or group" (kekerasan adalah perilaku tidak layak dan mengakibatkan kerugian atau bahaya secara fisik, psikologis, atau finansial, baik

${ }^{1}$ Abu Hurairah, Kekerasan terhadap Anak: Fenomena Masalah Sosial Krisis di Indonesia (Bandung : Nuansa (Anggota IKAPI), 2006), h.36.

39 
yang dialami individu maupun kelompok).Sedangkan kekerasan terhadap anak (child abuse) adalah istilah yang biasa digunakan untuk menyebut kekerasan terhadap anak.

Kekerasan Seksual terhadap anak menurut pasal 13 UU Perlindungan Anak adalah perlakuan: diskriminasi; eksploitasi, baik ekonomi maupun seksual; penelantaran; kekejaman, kekerasan, dan penganiayaan; ketidakadilan; dan perlakuan salah lainnya. Dalam penjelasan pasal 13 ini diuraikan bahwa perlakuan diskriminasi, misalnya perlakuan yang membeda-bedakan suku, agama, ras, golongan, jenis kelamin, etnis, budaya dan bahasa, status hukum anak, urutan kelahiran anak, dan kondisi fisik dan/atau mental. Perlakuan eksploitasi, misalnya tindakan atau perbuatan memperalat, memanfaatkan, atau memeras anak untuk memperoleh keuntungan pribadi, keluarga, atau golongan. Perlakuan penelantaran, misalnya tindakan atau perbuatan mengabaikan dengan sengaja kewajiban untuk memelihara, merawat, atau mengurus anak sebagaimana mestinya. Perlakuan yang kejam, misalnya tindakan atau perbuatan secara zalim, keji, bengis, atau tidak menaruh belas kasihan kepada anak. Perlakuan kekerasan dan penganiayaan, misalnya perbuatan melukai dan/atau mencederai anak, dan tidak semata-mata fisik, tetapi juga mental dan sosial. Perlakuan ketidakadilan, misalnya tindakan keberpihakan antara anak yang satu dan lainnya, atau kesewenang-wenangan terhadap anak.Perlakuan salah lainnya, misalnya tindakan pelecehan atau perbuatan tidak senonoh kepada anak.

Marzuki Umar Sa'abah mengemukakan (child abuse) adalah tindakan orang dewasa terhadap anak dengan cara yang disadari ataupun tidak yang berakibat menganggu proses tumbuh kembang anak. Sehingga dapat menimbulkan cacat fisik, mental bahkan kematian pada anak. ${ }^{2}$

Bentuk-bentuk Kekerasan Seksual terhadap Anak, Bentuk-bentuk kekerasan Seksual terhadap anak menurut Mieke Diah Anjar Yanti adalah sebagai berikut : ${ }^{3}$

Kekerasan fisik adalah tindakan yang menyebabkan rasa sakit atau potensi menyebabkan sakit yang dilakukan oleh orang lain, dapat terjadi sekali atau berulang kali seperti dipukul, ditendang, ditempeleng, dijewer, dicubit, dilempar dengan benda keras, dijemur di bawah terik sinar matahari.

Kekerasan seksual adalah keterlibatan anak dalam kegiatan seksual yang tidak dipahaminya seperti perlakuan tidak senonoh dari orang lain, kegiatan yang menjurus pada pornografi, perkataan-perkataan porno, perbuatan cabul dan

\footnotetext{
${ }^{2}$ Marzuki Umar Sa'abah, Perilaku Seks Menyimpang dan Seksualitas Kontemporer Umat Islam, (Yogyakarta : UII Pres, 2006), h. 91.

${ }^{3}$ Mieke Diah Anjar Yanit, dkk., Model Sistem Monitoring dan Pelaporan Anak dan Perempuan Korban Kekerasan, (Propinsi Jateng : Bapenas 2006), h. 9-11. 
persetubuhan pada anak-anak yang dilakukan orang lain dengan tanpa tanggung jawab, tingkatan mendorong atau memaksa anak terlibat dalam kegiatan seksual yang melanggar hukum seperti dilibatkan pada kegiatan prostitusi.

Kekerasan psikis adalah segala sesuatu yang dapat menyebabkan terhambatnya perkembangan psikologis anak seperti kata-kata yang mengancam, menakutnakuti, berkata-kata kasar, mengolok-olok, perlakuan diskriminatif, membatasi kegiatan sosial dan kreasi.

Kekerasan ekonomi (eksploitasi komersial) adalah penggunaan anak untuk bekerja dan kegiatan lainnya demi kebutuhan orang tuanya atau orang lain seperti menyuruh anak bekerja secara berlebihan, menjerumuskan anak kepada dunia prostitusi untuk kepentingan ekonomi.

Tindak pengabaian dan penelantaran adalah ketidakpedulian orang tua, orang yang bertanggung jawab atas anak pada kebutuhan mereka seperti pengabaian pada kesehatan anak, pengabaian dan penelantaran pada pendidikan anak, pengabaian pada pengembangan emosi, penelantaran pada pemenuhan gizi, pengabaian dan penelantaran pada penyediaan perumahan, pengabaian pada kondisi keamanan dan kenyamanan.

\section{B. Faktor-faktor Penyebab Kekerasan seksual terhadap anak}

Kekerasan seksual yang terjadi terhadap anak dapat terjadi karena beberapa faktor, yaitu: Dari Orang tua, Orang tua sebagai sarana edukasi yang harusnya memberikan pengetahuan terhadap anak, agar secara tidak langsung orang tua memberikan proteksi terhadap si anak.

Kurangnya pengetahuan yang diperoleh anak tentang batasan pergaulan terhadap lawan jenis, hal ini jelas akan sangat mempengaruhi terjadinya kekerasan seksual terhadap anak dimana anak dibiarkan berkumpul dan bergaul dengan lawan jenis tanpa ada orangtua yang mengawasi. Padahal sebagaimana telah dijelaskan dalam hadis nabi, Rasulullah bersabda : "Suruhlah anak-anakmu shalat ketika mereka berumur tujuh tahun, dan pukullah mereka (tanpa menyakitkan jika tidak mau shalat), ketika mereka berumur sepuluh tahun; dan pisahkanlah tempat tidur mereka." (HR. Abu Dawud). Dalam hadis ini dijelaskan bagaimana islam mengatur pergaulan terhadap lawan jenis, pada umur tertentu anak-anak sudah memiliki kemampuan untuk menyadari perbedaan kelamin, hal ini disebut sinnut tamyiz dimana pada umumnya terdapat pada anak-anak yang berusia 10 tahun.

Dari peralatan multimedia atau gadget, Tersebarluasnya penggunaan ponsel pintar dikalangan anak-anak juga menjadi salah satu faktor penyebab terjadinya kekerasan seksual pada anak, dimana anak di usia yang masih labil sudah terbiasa 
melihat gambar atau tontonan yang sifatnya pornografi, hal ini tentu akan menggangu imaginasi dan kreatifitas anak.

Gaya hidup anak, Keterbatasan ekonomi dan Gaya hidup juga termasuk salah satu faktor penyebab terjadinya kekerasan seksual terhadap anak, dimana jaman sekarang anak-anak hampir selalu punya idola yang dijadikan sebagai kiblat gaya dan penampilan, tidak jarang anak-anak usia belia yang kurang mampu tetap ingin memenuhi gaya hidupnya layaknya orang yang mampu, hal ini justru dimanfaatkan oleh segelintir orang yang tidak bertanggung jawab.

Penyakit masyarakat, Minuman keras dan obat-obatan daftar G juga masih menjadi salah satu faktor yang bertanggung jawab atas terjadinya kekerasan seksual terhadap anak di kelurahan Tamparang Keke, Kecamatan Mamajang, Kota Makassar. Padatnya pemukiman, akses gang yang sempit, dan masih seringnya perilaku minum minuman keras disudut-sudut gang menambah besarnya peluang terjadinya tindak kekerasan seksual terhadap anak yang hendak melintas melewati gang tersebut.

Keluarga disfungsional, Keluarga yang mengalami disfungsi punya dampak signifikan terhadap sang anak. Masalah berkepanjangan yang dialami oleh keluarga hingga menyita energi psikis dan fisik, hingga mempengaruhi interaksi sosial, situasi demikian sangat mempengaruhi kondisi emosi anak dan lebih jauh mempengaruhi perkembangan kepribadiannya.

Kekerasan lingkungan, Tak dapat dipungkiri bahwa kekerasan seksual yang terjadi terhadap anak selama ini juga terjadi karena adanya faktor lingkungan, yaitu: Adanya budaya kekerasan : seseorang melakukan kekerasan seksual karena dirinya berada dalam suatu kelompok yang sangat toleran terhadap tindakan kekerasan. Anak yang tumbuh dalam lingkungan tersebut memandang kekerasan hal yang biasa / wajar.

Mengalami sindrom Stockholm : Sindrom Stockholm merupakan suatu kondisi psikologis dimana antara pihak korban dengan pihak aggressor terbangun hubungan yang positif dan later on korban membantu aggressor mewujudkan keinginan mereka. Contoh, kekerasan seksual yang terjadi ketika anak yang lebih tua melakukan kekerasan seksual pada anak yang lebih muda, sikap yang seperti ini akan terus berlangsung.

\section{PENUTUP}

\section{A. Kesimpulan}

Berdasarkan pembahasan diatas maka, disimpulkan bahwa Peranan hukum Perlindungan Anak Sesuai pasal 55 Undang-undang Nomor 35 Tahun 2014 sudah diterapkan namun kekerasan seksual terhadap anak masih terjadi karena 
ketidak tahuan orang tua tentang aturan yang ada, kurangnya edukasi dan pengawasan dari orang tua memperbesar peluang terjadinya kekerasan seksual terhadap anak baik itu terjadi di media sosial, lingkungan bertetangga maupun lingkungan terdekat yakni keluarga.

\section{B.Saran -Saran}

Anak sangat membutuhkan kasih sayang, membutuhkan perhatian, anak memiliki rasa, sebagai orang tua, perlu memberikan edukasi terhadap terjadinya kekerasan seksual. Orang tua harusnya lebih dekat dengan anak baik disaat anak susah maupun senang dengan selalu siap menjadi sarana berbagi dengan anak., Dampak yang timbul akibat dari kekerasan seksual yang dialami oleh anak, seorang anak akan menganggap bahwa, memukul, mencubit, menjambak rambut, atau menyakiti orang lain adalah hal yang boleh dilakukan ketika ada yang membuat anak tersebut marah. Maka selayaknyalah selaku orang tua dapat mengantisipasi hal yang seperti ini. Agar anak tidak melakukan kekerasan seksual terhadap orang lain, sebaiknya sebagai orang tua yang bijak senantiasa memberikan keteladanan yang baik kepada anak. Dengan demikian ketika anak melakukan sebuah kekeliruan sebaiknya cepat disadarkan dengan penuh lemah lembut, namun jika anak sudah terlanjur melakukan sebuah kesalahan, hendaknya mendapatkan sanksi yang sesuai dengan peraturan perundang-ungdangan yang berlaku. 


\section{DAFTAR PUSTAKA}

Abu Hurairah. Kekerasan terhadap Anak: Fenomena Masalah Sosial Krisis di Indonesia, Bandung: Nuansa (Anggota IKAPI), 2006.

Johan Galtung. Kekuasaan dan Kekerasan. Yogyakarta: Kanisius, 1992.

Kitab undang-undang hukum pidana

Kitab Undang-undang Hukum Perdata Pasal 330 Kitab Undang-undang Hukum Perdata (KUHPerdata).

Marzuki Umar Sa'abah. Perilaku Seks Menyimpang dan Seksualitas Kontemporer Umat Islam. Yogyakarta: UII Pres, 2006.

Mieke Diah Anjar Yanit, dkk. Model Sistem Monitoring dan Pelaporan Anak dan Perempuan Korban Kekerasan. Propinsi Jateng: Bapenas, 2006.

R. Soesilo. Kitab Undang-Undang Hukum Pidana Serta Komentarnya Pasal Demi Pasal. Bogor: Politea, 1991.

Soejono Sukanto. Kriminologi (Pengantar Sebab-sebab kejahatan). Bandung: Politea, 1987.

Topo Santoso. Kriminologi. Jakarta: Grafindo Persada, 2002.

Undang-undang Nomor 4 Tahun 1979 tentang Kesejahteraan Anak.

Undang-Undang Nomor 3 Tahun 1997 tentang Pengadilan Anak.

Undang-Undang Nomor 35 Tahun 2014 tentang Perlindungan Anak. 